\title{
SALUD
}

\section{Vivencias de pacientes con diagnóstico de esclerosis múltiple del Instituto de Previsión Social, Hospital Central. Año 2015}

\author{
María Raquel Martínez Garay¹, Mónica Ruoti²
}

\section{Resumen}

Introducción: El tema del presente trabajo surge de un interés de obtener mayor información acerca de la Esclerosis Múltiple (EM), no solo de la enfermedad en sí misma, en sus aspectos mórbidos y terapéuticos, sino fundamentalmente de las personas que reciben su diagnóstico y tratamiento, conocer cómo la asumen y vivencian.

La esclerosis múltiple (EM) es una enfermedad inflamatoria de la mielina del sistema nervioso central, crónica, de causa desconocida y que en su evolución produce déficits motores, sensitivos, autonómicos y psíquicos. Es considerada la segunda causa de discapacidad en adultos jóvenes. La tasa de prevalencia es de $5.7 \%$ por cada 100.000 habitantes paraguayos.

Objetivo: Describir las vivencias de pacientes con diagnóstico de Esclerosis Múltiple del Instituto de Previsión Social, Hospital Central en el año 2015.

Material y Método: El estudio es de enfoque cualitativo, de diseño fenomenológico y de alcance descriptivo. La población de estudio son pacientes, con diagnóstico de Esclerosis Múltiple, del Hospital Central Instituto de Previsión Social, que ingresan a la Institución en forma ambulatoria (consultorio y Hospital Día) o para internación en el servicio de Neurología. La muestra constó de 15 participantes que se seleccionó en base a criterios y tamaños que se obtuvieron hasta la saturación de datos. La participación fue voluntaria y cada paciente expresó con libertad. Se empleó la técnica de entrevistas a profundidad en base a una guía de preguntas y la revisión del expediente clínico para obtener los datos sociodemográficos y clínicos. Para la recolección de datos, las entrevistas fueron grabadas en audio, las mismas se realizaron en el Hospital Central, Instituto de Previsión Social, servicio de Neurología, a medida que acudían al servicio, se realizaba la invitación y acuerdo para la entrevista.

Cabe mencionar que todas aceptaron realizar el mismo día de la propuesta y las grabaciones se llevaban a cabo desde el lugar de internación o sala de reuniones del mismo servicio, para ello fue necesaria una sola entrevista. En

1. Universidad Católica Nuestra Señora de la Asunción, Paraguay.

Tesis presentada como requisito para la obtención del Grado de Magíster en Enfermería con Énfasis en Gestión de Enfermería.

2 Tutora de Tesis.

E-mail: maria_raquel_82@hotmail.com

DOI: 10.26885/rcei.foro.2017.149 
cuanto al procesamiento y análisis se realizaron varias lecturas de todas las entrevistas transcriptas textualmente en formato Word. Se agruparon los datos por categorías, se obtuvieron 7 categorías, 20 sub categorías y 4 categorías emergentes, las cuales fueron volcadas en matrices, para ser analizadas e interpretadas. Cabe destacar que para los datos sociodemográficos y clínicos fueron utilizadas las tablas. Cada dimensión es visualizada en forma resumida por medio de diagramas que sintetizan los resultados obtenidos, y de esta manera permiten una mayor apreciación. Se solicitó con la autorización de las autoridades correspondientes, el consentimiento informado, firmado por los pacientes.

Prevaleció la seguridad de los beneficiarios. Se dio a conocer los beneficios de la investigación. Se les aclaró que la información obtenida, más los resultados de la investigación, se maneja confidencialmente.

Resultados: La mayoría de los entrevistados pertenecen al sexo femenino, debutaron con la enfermedad en edad adulta joven, no estaban en conocimiento del significado de la enfermedad y tras el conocimiento del primer diagnóstico presentaron diversos sentimientos, entre ellas sosiego, tristeza y una actitud suicida. Cabe resaltar que la mayoría manifestaron recibir el apoyo por parte de sus familiares, no obstante reconocieron que de alguna forma sobrecargan de trabajo al cuidador, teniendo en cuenta que la debilidad de miembros inferiores prevaleció como afección física. Ante ésta situación, expresaron diversas estrategias para afrontar la enfermedad, como la fe, el optimismo y la lucha diaria.

Las manifestaciones de la enfermedad inician en la edad adulta joven, con frecuencia en el sexo femenino, este estudio guarda relación con la investigación. El informe del primer diagnóstico fue crucial, debido a que ya tendría "un nombre" la enfermedad, en una revista científica se expone: "los pacientes se mueven en la condición paradójica del alivio en primer lugar, ya que reciben un nombre a su padecer.

En el otro extremo, la reacción fue diferente, se revela la decisión que se estuvo a punto de tomar, el suicidio; referente a ello, un artículo de revista española, expone la desesperación de pacientes ante el ataque agudo de inicio de la enfermedad, centraba en la amargura, con un fuerte impacto por la noticia y vivencias emocionales muy intensas ante el diagnóstico.

En la mayoría de los casos, los entrevistados manifestaron que en algún momento sienten que sobrecargan de trabajo a familiares, por el hecho de la incapacidad parcial o total; en una investigación hecha en España, algunos pacientes expresan sentimientos de culpa, por todos los cambios que la familia está sufriendo debido a la enfermedad.

Ante la enfermedad crónica, los entrevistados expresan haber transitado por situaciones comunes de impacto emocional, Belda afirma en una investigación, que se trata en realidad de la lucha de cada día, toma de actitud positiva para sobrevivir el día a día. 
Conclusiones: Los entrevistados vivencian de manera diferente, dependiendo de las circunstancias en las que se presente y la situación por la que cada persona esté atravesando, es necesario fomentar investigaciones respecto al paciente como un ser holístico e implementar propuestas de mejora con un equipo multidisciplinario, de esta manera se optimizará el cuidado, mejorará sus vivencias y su calidad de vida.

Palabras clave: esclerosis múltiple, vivencias.

\section{Referencias}

Belda, C. P. (2012). Afrontando la esclerosis múltiple: sentimientos y temores. Portularia: Revista de Trabajo Social, 2(12), 117-125.

Ministerio de Salud Pública y Bienestar Social. (29 de mayo de 2013). Día mundial de la esclerosis múltiple: Paraguay registra 318 casos por cada 100000 habitantes. Recuperado de http://www.mspbs.gov.py/ V2/17020

Salinas V., Rogero P., Oña, A. \& Vergara, M. (2012). Descubriendo el significado de los fenómenos cronicidad, progresión y singularidad en el diagnóstico de la esclerosis múltiple. Index Enferm. 21(3). Recuperado de http:// scielo.isciii.es/scielo.php?pid=S113212962012000200004\&script=sci_ arttext\&tlng=pt 